\title{
Insect Pollinators in CGMS Hybrid Seed Production of Cajanus cajan
}

\author{
LI Zheng-Hong ${ }^{1, * *}$, LIANG Ning ${ }^{1, * *}$, MA Hong ${ }^{1}$, Kul Bhushan SAXENA $^{3}$, YANG Tao ${ }^{2}$, LIU Xiu-Xian ${ }^{1}$, \\ and ZONG Xu-Xiao ${ }^{2, *}$ \\ ${ }^{1}$ Research Institute of Resources Insects, Chinese Academy of Forestry, Kunming 650224, China \\ ${ }^{2}$ Institute of Crop Sciences, Chinese Academy of Agricultural Sciences, Beijing 100081, China \\ ${ }^{3}$ International Crops Research Institute for the Semi-Arid Tropics, Patancheru 502324, India
}

\begin{abstract}
Pigeonpea [Cajanus cajan (L.) Millspaugh] is the only shrubby food legume crop with drought tolerance in the world. Insect pollinators are essential to flower pollination in cytoplasmic genetic male sterility (CGMS) pigeonpea lines, and the species, abundance, and visiting frequency of insect pollinators are the key factors for pigeonpea hybrid production. More than 46 species of insects have been reported to be flower visitors in the open field for pigeonpea production outside China, of which Megachile spp. are the major pollinators. In this study, the species, abundance, and visiting frequency of flower-visiting insects at flowering stage, as well as hybrid yield of pigeonpea, were investigated in the pigeonpea hybrid production field in Yuanmou County, Yunnan Province, China, using CGMS-based ICPH2671 hybrid. A total of 25 species of flower-visiting insects were detected, including 5 major pollinator species, Megachile velutina Sm., Megachile sp-5, Xylocopa tenuiscapa Westw., Apinae sp-1, and Megachile sp-2. At the blooming stage, the flower-visiting insects visited each primary branch at a frequency of 2.8 times per $10 \mathrm{~min}$ for the CGMS male sterile line, while at a frequency of 5.2 times per $10 \mathrm{~min}$ for the CGMS restorer line. This indicated the preference of flower-visiting insects to the flowers of restorer line. This significant difference between the male sterile and the restorer lines resulted in very similar dry seed yields of the male sterile line ( $383.7 \mathrm{~g}$ per plant) and the restorer line ( $357.0 \mathrm{~g}$ per plant). Therefore, enough pollens can been transported from the restorer line to the male sterile line by insect pollinators, even much less visiting frequency on the flowers of male sterile line compared to that of the restorer line.
\end{abstract}

Keywords: pigeonpea (Cajanus cajan); CGMS system; insect pollinators; hybrid seed production

Pigeonpea [Cajanus cajan (L.) Millspaugh] is an evergreen perennial hardy shrub legume species with erect woody stem and branches. It is cultivated in arid and semiarid tropics/subtropics between $32^{\circ} \mathrm{S}$ and $\mathrm{N}$, as an annual and perennial crop ${ }^{[1]}$. Pigeonpea is planted for dry seeds as grains, fresh green peas as delicious and nutritional vegetable, tender branches and leaves (fresh and dry) as fodders, and honey bees husbandry as honey resources when blooming. As the only food legume crop with woody stems, its woody branches are also used as fire wood, construction materials, paper stocks, and basket knitting. The living adult plants of pigeonpea can be lac insect (Laccifer lacca) hosts for lac production ${ }^{[2]}$. The root system of pigeonpea is very strong and aggressive when the crop is planted as shelter forest on the steep slope; it develops itself well to reduce the erosion of soil and water and fix gas nitrogen as active nitrogen fertilizer in the field by developing its root nodules with rhizobia symbiotically. The fallen leaves of pigeonpea improve the soil structure and enrich its organic matter. Famers harvest fresh pods and dry grains of pigeonpea at the same time. Growers often sow pigeonpea at the field boundaries and as fences around their home yards ${ }^{[1-3]}$. The agroforestry on coverage of steep bare slops for fodder production, monocropping on dry slopes for food production, intercropping with maize and fruit trees for dry seed and green seed vegetable production are the main usages of pigeonpea crops in the major production area

Received: 27 March 2011; Accepted: 25 July 2011.

* Corresponding author. E-mail: zongxx@mail.caas.net.cn

** Contributed equally to this work.

Copyright (C) 2011, Crop Science Society of China and Institute of Crop Sciences, Chinese Academy of Agricultural Sciences. Published by Elsevier BV. All rights reserved. Chinese edition available online at http://www.chinacrops.org/zwxb/

DOI: $10.1016 / \mathrm{S} 1875-2780(11) 60057-6$ 
of pigeonpea in China ${ }^{[3]}$. There are more than 50 pigeonpea-producing countries, covering a total annual area of 5.2 million hectares ${ }^{[4]}$. Based on growing area, pigeonpea ranks the sixth largest in the 20 food legume crops, following common bean (Phaseolus vulgaris), chickpea (Cicer aritinum), cowpea (Vigna unguiculata), lentil (Lens culinaris), and pea

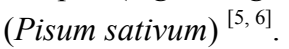

The traditional pigeonpea cultivars are normal pure lines. In 1991, the International Crops Research Institute for Semi-Arid Tropics (ICRISAT) at Patancheru, India, developed the first genetic male sterility (GMS)-based hybrid pigeonpea variety, ICPH8, which was released in a limited area in India. Due to $50 \%$ female plants permanently existed in the male sterility lines caused by dominant genetics of GMS in its hybrid seed production system, the labor cost for identification and removal of those male fertile plants is extremely high. The high cost of GMS hybrid seed production system resulted in the failure of ICPH8 ${ }^{[7]}$. To solve the problem, ICRISAT developed the cytoplasmic genetic male sterility (CGMS)based hybrid technology and officially released a new hybrid pigeonpea variety, ICPH2671, in 2008. This CGMS-based hybrid pigeonpea variety was resistant to sterility mosaic and wilt diseases, with $100 \%$ male sterile plants in the CGMS line, which made large scale production of hybrid seeds available. The results of experiments carried out in multiple locations in India from 2007 to 2009 demonstrated that ICPH2671 is a prosperous variety in pigeonpea production because its average yield in 317 hectares was $30 \%$ higher than that of the control ${ }^{[8]}$. Thus, pigeonpea becomes the first food legume crop that successfully applies heterosis in the world.

Pigeonpea is an often out-crossing crop with out-crossing rates ranging from $12.6 \%$ to $45.9 \%{ }^{[9-16]}$. Forty-six species of insects have been reported to be flower visitors in pigeonpea production fields, of which Megachile spp. are the major insect pollinators ${ }^{[17]}$. CGMS-based pigeonpea hybrid seed production systems highly depend on insect pollinators to transfer pollen from the restorer line to the pistils of male sterile line for pod and seed setting. Therefore, the species and population size of flower visiting insects are critical in the pigeonpea hybrid seed production. However, the relationship between species of insect pollinators and yield of pigeonpea hybrid seed has been rarely studied in China.

In 2006, the Research Institute of Resources Insects of Chinese Academy of Forestry introduced a batch of pigeonpea germplasm from ICRISAT, including CGMS sterile line (A-line), maintainer line (B-line), and restorer line (R-line), of which ICPH2671 was identified as a high-yielding hybrid cultivar with good stability in Yunnan Province; thereafter, the A-, B-, and R-lines of ICPH2671 were successfully used in seed production ${ }^{[18]}$. However, the size of field was found to affect the yield of hybrid seed in the seed-producing test. We speculated the possible reason was related to the insect pollinator, because the population density and visiting frequency of the flying pollinator were greatly controlled by field size. To confirm this speculation, we investigated the species, abundance, and visiting frequency of flower-visiting insects at the flowering stage of CGMS-based ICPH2671 hybrid seed production system (A-line and R-line) in this study, and analyzed the relationships between these factors and hybrid yield. The result was expected to guide field design in pigeonpea hybrid production in Yunnan Province.

\section{Materials and methods}

\subsection{General conditions of experimental location}

The experiment was conducted in Matou village (25 38 $27^{\prime \prime}$ N, 101 ${ }^{\circ} 54^{\prime} 10^{\prime \prime}$ E, altitude $1125 \mathrm{~m}$ ), Yuanmou County, Yunnan Province, where belongs to dry and hot valley ecological zone with general climate parameters as follows: annual mean temperature $21.9^{\circ} \mathrm{C}$, maximum temperature $42{ }^{\circ} \mathrm{C}$, minimum temperatures $-2{ }^{\circ} \mathrm{C}, \geq 12{ }^{\circ} \mathrm{C}$ duration $349 \mathrm{~d}$, annual accumulated temperature $7796{ }^{\circ} \mathrm{C}$, annual precipitation $613.8 \mathrm{~mm}$, and 4.4 degree of dryness ${ }^{[19]}$. Savanna red soil is distributed on most land in this area, and torrert soil is in the resting land. The land is covered with natural savanna shrub-grass and artificial vegetation mainly in multiple eucalyptus species.

\subsection{Experimental design}

On 4 June 2007, parents of ICPH2671 hybrid, ICPA2043 (A-line) and ICPL87119 (R-line), were sown in a field of 220 $\mathrm{m}^{2}$. Every 4 rows of A-line were separated by 1 row of R-line, with $1 \mathrm{~m}$ interval between rows. Each row had 12 plants in 1 $\mathrm{m}$ spacing between plants. Field investigations were conducted from 25 to 27 October 2007 (clear with few clouds), when pigeonpea entered blooming stage.

\subsection{Investigation of flower-visiting insects}

Flower-visiting insects were randomly immeshed in the experimental field from 8:00 a.m. to 20:00 p.m. at the interval of $1 \mathrm{~h}$, and immediately killed with insecticide. The insect specimens captured in 3 days were divided into Lepidoptera and others to be identified by Dr. ZHOU Cheng-Li from the Research Institute of Resources Insects, Chinese Academy of Forestry (Kunming, China), and Prof. LIANG Xing-Cai from Kunming Institute of Zoology, Chinese Academy of Sciences (Kunming, China), respectively. The flower-visiting frequency of major flower-visiting insects and their routine activities were also recorded.

The flower visits of target insects were tracked on 5 main branches of A-line or R-line randomly selected. From 8:00 A.M. to 18:00 P.M. on 25 and 26 October 2007, the observation was partitioned into 5 cycles with $2 \mathrm{~h}$ of a cycle. In each observation cycle, the behaviors of insects visiting A-line and R-line were recorded in the first and second hour in each observation cycle, with 10-minute continually tracked 
recording in each hour. Repeated visits to the same flower by the same insect were considered as independent visits with reduplicate counting. The visiting frequency was based on each branch within $10 \mathrm{~min}$.

The number of flower receiving insect visit within $1 \mathrm{~min}$ and the staying time per visit were investigated only for major insect species. Ten insects randomly selected from each species were observed.

\subsection{Yields of A- and R-lines of pigeonpea}

Fifteen plants randomly selected from the A-line and R-line plots each were harvested at the stage when $80 \%$ pods matured. The harvested seeds were weighted after naturally dried for $7 \mathrm{~d}$.

\subsection{Statistical analysis}

The software package SPSS13.0 was used for variance of analysis and correlation analysis.

\section{Results}

\subsection{Species of flower-visiting insects}

In the total of 208 insect individuals captured, 25 species were identified belonging to 5 orders and 15 families (Table 1). Megachile velutina, Megachile sp-5, Xylocopa tenuiscapa, Apidae sp-1, Megachile sp-2, Catopsilia pomona, and Danaidae chrysippus (Linnaeus), ranked the top 7 abundances, with the total abundance of $73.08 \%$. Megachilidae family was most popular, and $50.9 \%$ of captured insect individuals belong to 7 species under this family.

\subsection{Behavior characteristics of major flower-visiting insects}

2.2.1 Thumbprint of major flower-visiting insects and identification of major pollinators Megachile velutina, Megachile sp-2, and Megachile sp-5 exhibited a common visiting behavior of moving from one flower to another, but occasionally had repeated visits to the same flower. On an open flower, Megachile spp. first stretched their heads into the blooming flowers, with their front and middle legs standing on tropis of the flower and the post legs free in the air or grasping the lower part of tropis; and then pushed aside the tropis using the front legs to expose stamens and pistils and brush from bottom to top for collecting pollens on ventral brush, with the help of middle legs to fix the stamens and pistils. After visiting several flowers, Megachile spp. preferred staying on a branch

Table 1 Species and their relative abundance of insect pollinators in pigeonpea hybrid field in Yuanmou, Yunnan Province

\begin{tabular}{|c|c|c|c|c|}
\hline Order & Family & Species & Number of specimens & Relative abundance (\%) \\
\hline Hemiptera & Hemiptera: Coreidae & Anoplocnemis phasiara & 1 & 0.48 \\
\hline Coleoptera & Meloidae & Mylabris phalerata & 3 & 1.44 \\
\hline \multirow[t]{7}{*}{ Lepidoptera } & Danaidae & Danaidae chrysippus & 8 & 3.85 \\
\hline & Nymphalidae & Ariadne ariadne & 2 & 0.96 \\
\hline & Pierididae & Catopsilia pomona & 15 & 7.21 \\
\hline & & Eurema hecabe & 3 & 1.44 \\
\hline & Lycaenidae & Lampides boeticus & 3 & 1.44 \\
\hline & Hesperiidae & Parnar bada & 2 & 0.96 \\
\hline & Papilionidae & Papilio demoleus & 1 & 0.48 \\
\hline \multirow[t]{5}{*}{ Diptera } & Syrphidae & Syrphus nitens & 3 & 1.44 \\
\hline & & Eristalis tenax & 4 & 1.92 \\
\hline & & Lschiodon scutellaris & 2 & 0.96 \\
\hline & Tephritidae & Tephritidae sp. & 3 & 1.44 \\
\hline & Sciomyzidae & Sciomyzidae & 2 & 0.96 \\
\hline \multirow[t]{11}{*}{ Menoptera } & Xylocopidae & Xylocopa tenuiscapa & 23 & 11.06 \\
\hline & Apidae & Apinae sp. & 21 & 10.10 \\
\hline & & Anthophora sp. & 3 & 1.44 \\
\hline & Megachilidae & Megachile velutina & 43 & 20.67 \\
\hline & & Megachile rixator & 3 & 1.44 \\
\hline & & Megachile sp.1 & 3 & 1.44 \\
\hline & & Megachile sp.2 & 17 & 8.17 \\
\hline & & Megachile sp.3 & 5 & 2.40 \\
\hline & & Megachile sp.4 & 6 & 2.88 \\
\hline & & Megachile sp.5 & 25 & 12.02 \\
\hline & Sphecidae & Sphecidae sp. & 3 & 1.44 \\
\hline Total & & & 208 & 100.00 \\
\hline
\end{tabular}


of pigeonpea to glean pollen from head and thorax to ventral brush using the front and middle legs, respectively. When visiting a flower without fully blooming, Megachile spp. opened the petals using head and front legs before collecting pollen and nectar.

Xylocopa tenuiscapa has a flower-visiting behavior similar to honey bees, but flies faster than the latter. When visiting a blooming flower, this bee species stood on petals or stamens/pistils, and quickly siphoned nectar on the bottom of pistils with the proboscidal tube. Furthermore, X. tenuiscapa tended to aggressively open the incompletely blooming flowers, which accelerated blooming of pigeonpea. This species usually went through the whole inflorescence from one flower to another before leaving to another inflorescence, showing a high visiting frequency.

Apinae sp. usually landed on petals in the direction of the flower, with head, thorax, ventral, abdomen, and legs easily touching the stamens and pistils of flower. The bee used its head and front legs to help opening an early blooming flower before entering it to collect pollen and nectar. The visiting routine was from one flower to another.

Catopsilia pomona and D. chrysippus are butterfly species, which had similar flower-visiting behaviors, with high visiting speed and repeat visits to the same inflorescence after short flying in the air. When visiting flowers, they fixed the petioles or petals with their front legs and suck nectar with the stretched beaks, but occasionally touched pollen and chapiter of flowers. Therefore, both species showed extremely low efficiencies on out-crossing of pigeonpea.

Based on flower-visiting behavior, M. velutina, Megachile sp-5, X. tenuiscapa, Apinae sp., and Megachile sp-2 were identified as the major pollinators for pigeonpea.

\subsubsection{Visiting frequencies and staying time of major} pollinators The visiting times per minute per head varied greatly among the 7 major species, with the largest frequency of 8.9 flowers per minute per head for $X$. tenuiscapa and the lowest frequency of 2.5 flowers per minute per head in Apinae sp. The staying time per visit also showed a wide range in the 7 major pollinator species. Three species showed much longer stays (12.4-15.1 s) than other species, including both butterfly species. The longest and the shortest stays on flowers were observed in Apinae sp. and X. tenuiscapa, respectively, and the Megachilidae family had the medium staying time per visit among different bee species (Table 2).

\subsubsection{Diurnal rule of flower visiting in major insect} species Based on 3-day observation, bees (Hymenoptera order), butterflies (Lepidoptera order), and hover flies (Syrphidae family) started flower visiting activities at around 7:45 A.M., and reached peak visiting in period of 9:30-11:30 A.M. High temperature period between 12:30 to 15:00 P.M. resulted in inactive flower-visiting of the insects, while the second visiting peak arrived at 15:00-16:30 P.M. After 18:00 P.M., almost none flower visitor was observed.

The diurnal foraging activities were different among the 5 bee species and 2 butterfly species (Figs. 1 and 2). Xylocopa tenuiscapa exhibited 2 visiting peaks at 10:00-11:30 A.M. and 14:00-15:30 P.M. in a day, with quick decline after peaks; while other bee species showed several visiting peaks within a day, but the sizes of visiting population varied slightly. In the butterfly family, C. pomona (ð) showed the peak of visiting population around 13:00 P.M., while $D$. chrysippus showed the peaks around 9:00 A.M. and 13:00 P.M., respectively.

\subsection{Frequencies of insects visiting A- and R-lines and seed productions}

2.3.1 Visiting frequencies of insects From 8:00 A.M. to 18:00 P.M. of clear days, based on 5 primary branches of a plant, the visiting frequencies were 2.8 and 5.2 times per 10 min for A-line and R-line, respectively (Table 3). The visiting frequency of R-line was $85.71 \%$ higher than that of A-line $(P<0.05)$, which indicated that the flower-visiting insects prefer R-line with normal flowers rather than A-line with sterile pollens.

Table 2 Visiting frequency and stay of major pollinators on pigeonpea flowers in hybrid field in Yuanmou, Yunnan Province

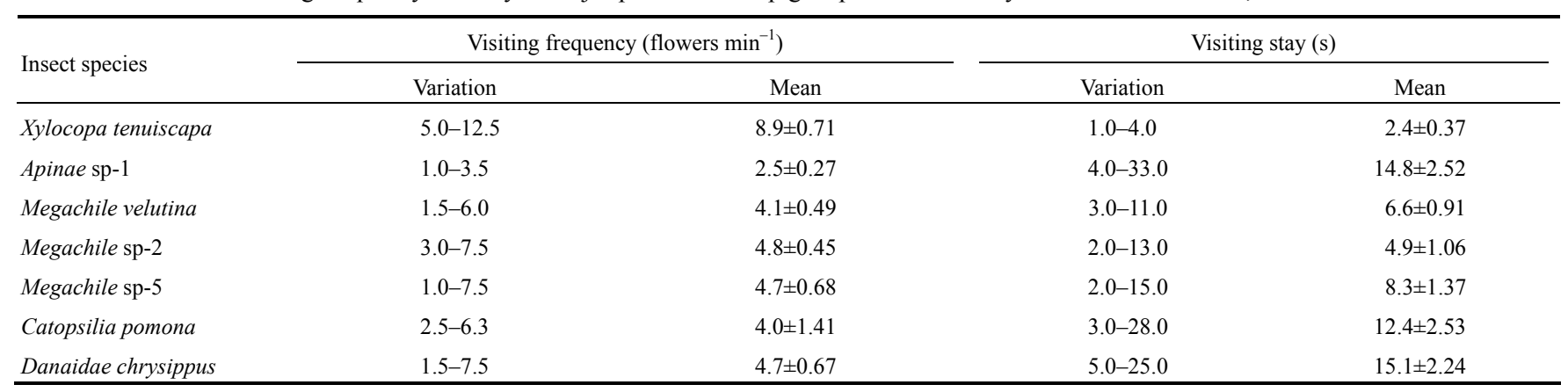




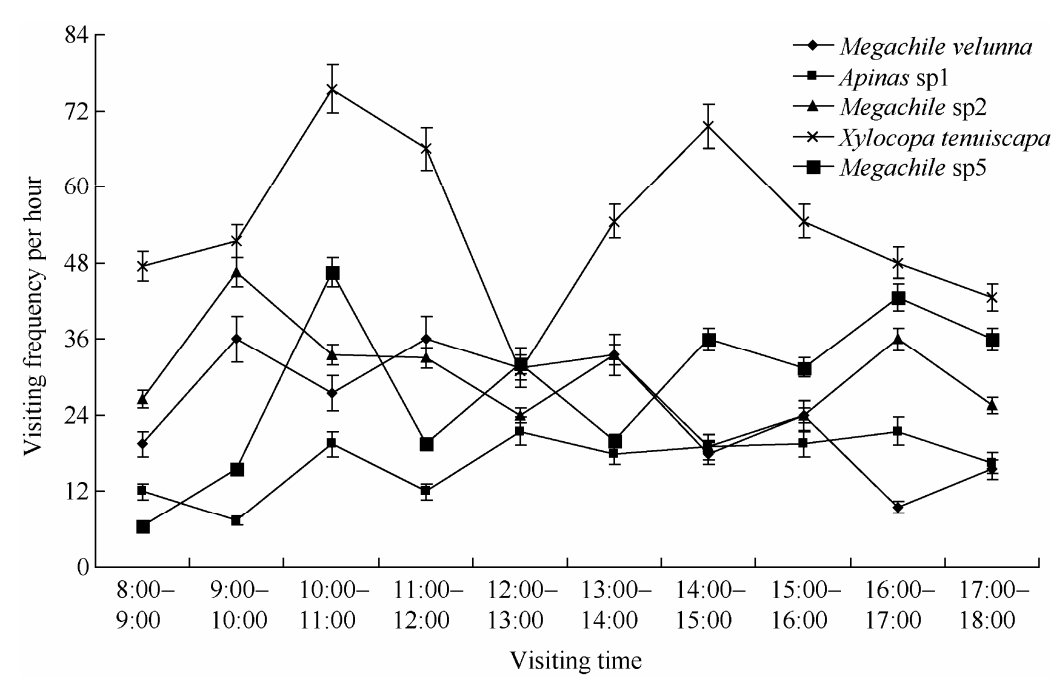

Fig. 1 Diurnal variation of bees foraging activity

Data are the means of 3-day observation. Vertical bars indicate the standard deviations.

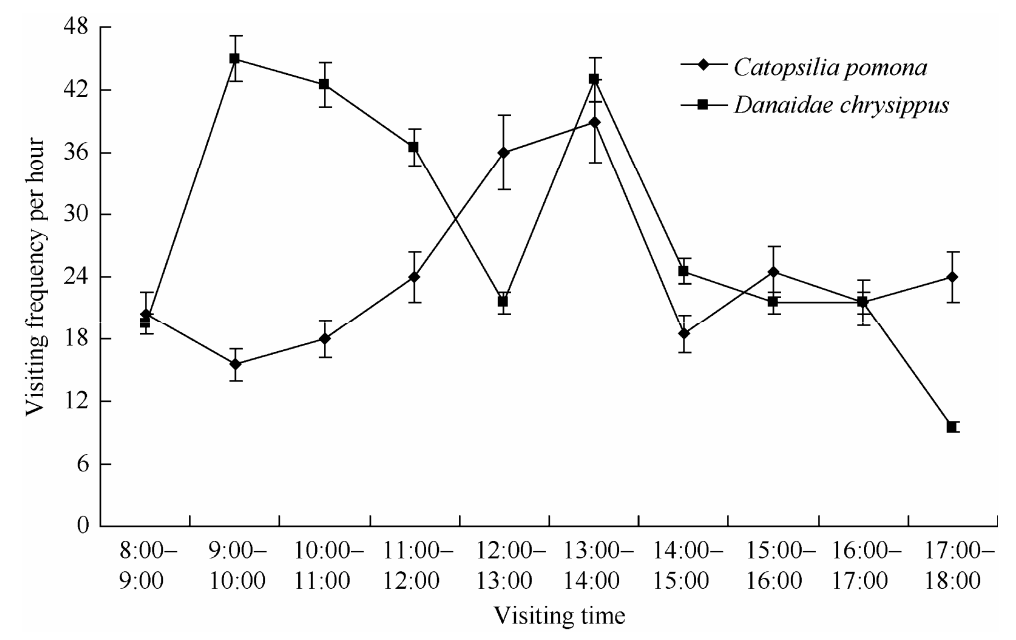

Fig. 2 Diurnal variation of butterflies foraging activity

Data are the means of 3-day observation. Vertical bars indicate the standard deviations.

Table 3 Flower-visiting frequencies of insects on primary branches of A-line and R-line (times per 10 min)

\begin{tabular}{|c|c|c|c|c|c|c|c|c|c|c|c|c|}
\hline \multirow{2}{*}{ Day } & \multicolumn{6}{|c|}{ A-line } & \multicolumn{6}{|c|}{ R-line } \\
\hline & 1 & 2 & 3 & 4 & 5 & Mean & 1 & 2 & 3 & 4 & 5 & Mean \\
\hline First day & 3.8 & 2.0 & 5.2 & 3.6 & 1.2 & 3.2 & 10.2 & 4.4 & 4.8 & 3.6 & 4.4 & 5.5 \\
\hline Second day & 2.8 & 1.4 & 3.6 & 3.2 & 1.0 & 2.4 & 6.4 & 6.6 & 4.4 & 3.8 & 2.8 & 4.8 \\
\hline Mean & 3.3 & 1.7 & 4.4 & 3.4 & 1.1 & 2.8 & 8.3 & 5.5 & 4.6 & 3.7 & 3.6 & 5.2 \\
\hline
\end{tabular}

Numbers 1 to 5 refer to the 5 plants of each line.

2.3.2 Seed yields of hybrid and R-line The average yield per plant of hybrid seed were $383.7 \pm 165.8 \mathrm{~g}$, with no significant difference to that of R-line seed $(357.0 \pm 125.1 \mathrm{~g})$. According to the plant densities, there were 8010 A-line plants and 1995 R-line plants in the experimental field. Theoretically, the yields were $3073.7 \mathrm{~kg} \mathrm{ha}^{-1}$ for the hybrid seed and 712.2 $\mathrm{kg} \mathrm{ha}^{-1}$ for the R-line seed. Thus, the total seed production was $3785.9 \mathrm{~kg} \mathrm{ha}^{-1}$. 


\section{Discussion}

\subsection{Major pollinators of pigeonpea}

After integrating evaluation of population size, behavior, flower-visiting activities, and amount of pollen carried, Williams ${ }^{[17]}$ indicated that the insects of Hymenoptera order are the major pollinators, especially the M. bicolor (Fab.) and $M$. conjuneta Smith, due to their body structures and feeding activities so coincided to that of pigeonpea flowers; most insect species of Hemiptera, Coleoptera, Lepidoptera, Hymenoptera, Homoptera, and Orthoptera have small contributions to out-crossing of pigeonpea, as they do not touch anthers and chapiters deliberately when visiting flowers; however, the insects from Syrphidae family are effective on out-crossing to some extent, as they are feeding on pollen and nectar. We have observed similar results in this study. A total of 25 species were captured in the hybrid seeds production field, of which 7 species were indentified to be major flower-visiting insects. Five species of Hymenoptera order, $M$. velutina, Megachile sp-5, X. tenuiscapa, Apinae sp., and Megachile sp-2, are pollinators of pegeonpea, while $C$. pomona and $D$. chrysippus are only feeding visitors because they seldom touch the anthers and chapiters of pigeonpea flowers with extremely low pollinating efficiency. However, the most efficient pollinator species to pigeonpea in Yuanmou is still in question, because pollinating efficiency of a species in a certain area has close relationships with insect population size, flower-visiting frequency, staying time per visit, and pollen load of an individual. This should be studied in details in future.

\subsection{Preference of flower-visiting insects}

It has been shown that flower color, flower scent, and nectar quantity are the major factors affecting visit frequencies of honey bees; white, yellow, and purple flowers containing flavone and flavonol are most attractive to honey bees, and the heavy scents of mature pollen and flower ready for receiving pollen are also in favor of calling pollinator bees ${ }^{[20,21]}$. In a certain area, honey bees prefer plant species with large amount of nectar flow ${ }^{[20,21]}$.

Williams ${ }^{[17]}$ has pointed out that Apidae (honey bees) and Megachilidae families have obvious choices of flower structure rather than flower color when visiting pigeonpea flowers. For example, Apis dorsata is fond of a mutant pigeonpea, which possesses the flower structure with exposed androecium and chapiter due to the falky and opened tropis; whereas Megachile spp. prefer visiting flowers with normal structure ${ }^{[17]}$.

In this study, we first observed the preference of pollinator insects on pigeonpea lines with different fertilities. We found that R-lines received more visits of flower-visiting insects than A-lines, with $96.2 \%$ higher visiting frequency on R-lines.
Pigeonpea A-lines are male sterile genotypes with no pollen in the flowers, which results in less attraction to flower-visiting insects that are fed on nectar and pollen. However, we cannot speculate whether the amount of nectar flow and the scent of flowers also explain the difference visiting frequencies between R-line and A-line based on the results in this study.

\subsection{Correlation between visiting frequency of flower-visiting insects and hybrid seed production}

The area of field to produce ICPH2671 hybrid seeds was 0.35 hectare. At blooming stage, the flower-visiting frequencies of insects per primary branch within $10 \mathrm{~min}$ were 2.8 times for the CGMS line and 5.2 times for the corresponding restorer line. As a resulted, the $\mathrm{F}_{1}$ hybrid and restorer line had similar dry seed yields (383.7 and $357.0 \mathrm{~g}$ per plant, respectively). This indicated that such flower-visiting frequencies are enough for pollen transportation from the restorer to the CGMS line by pollinator insects. These flowervisiting frequencies cannot be simply used as a principle in hybrid seed production in pigeonpea, since the species and population sizes of flower-visiting insects are loosely related to field location, season, and surrounding plant flora. Furthermore, the maximum seed yields and economic benefit are also important goals pursued in hybrid seed. These factors should be involved in future studies of flower-visiting insects.

\section{Conclusions}

Twenty-five species of flower-visiting insects were detected in the field of pigeonpea hybrid seed production in Yuanmou, Yunnan Province. Among them, M. velutina, Megachile sp-2, Megachile sp-5, X. tenuiscapa, and Apidae sp. were identified as major pollinator species. At blooming stage, the frequencies of insects visiting flowers on each primary branch were 2.8 and 5.2 times per $10 \mathrm{~min}$ for the CGMS and restorer lines, respectively. Such visiting frequencies resulted in similar seed yields of hybrid (383.7 g per plant) and R-line (357.0 g per plant). This indicated good pollinations of the CGMS and restorer lines in hybrid seed production of pigeonpea under the experimental condition.

\section{Acknowledgments}

This work was supported by the International Cooperative Research Program from the Ministry of Science and Technology of China (2008DFA30970), the Crop Genetic Resources Protection Program (2008DFA30970), and the earmarked fund for Modern Agro-industry Technology Research System (CARS-09), the Key Technologies R\&D Program of Yunnan Province, China (2006NG27), and the Program of Introducing International Super Agricultural Science and Technology (2007-4-05). 


\section{References}

[1] Nene Y L, Hall S D, Sheila V K. The Pigeonpea. UK: CAB International, 1990

[2] Li Z H, Zhou C H, Gu Y, Zhang J Y. Proceedings and prospects of pigeonpea research and utilization in China. For Res, 2001, 14: 674-681 (in Chinese)

[3] Zong X X. The Pigeonpea. Dalian: Dalian Press, 2003. pp 1-3 (in Chinese)

[4] FAOSTAT. Statistical Database. http://www.fao.org/

[5] Zong X X, Guan J P, Li Z H, Bao S Y, Gu Y, Luo R H. Descriptors and Data Standards for Pigeonpa (Cajanus spp.). Beijing: China Agriculture Press, 2006. pp 1-3 (in Chinese)

[6] Saxena K B, Nadarajan N. Prospects of pigeonpea hybrids in Indian agriculture. Electr J Plant Breed, 2010, 1: 1107-1117

[7] Saxena K B, Chauhan Y S, Johansen C, Singh L. Recent developments in hybrid pigeonpea research. In: Proceedings of Workshop on New Frontiers in Pulses Research and Development, Kanpur, India, 10-12 November, 1989. pp 58-69

[8] Mula M G, Saxena K B. Lifting the Level of Awareness on Pigeonpea: A Global Perspective. Patancheru, Andhra Pradesh, India: International Crops Research Institute for the Semi-Arid Tropics, 2010. p 12

[9] Saxena K B, Singh L, Gupta M D. Variation for natural out-crossing in pigeonpea. Euphytica, 1990, 39: 143-148

[10] Saxena K B, Kumar R V. Insect-aided natural out-crossing in four wild relatives of pigeonpea. Euphytica, 2010, 173: 329-335

[11] Bhatia G K, Gupta S C, Green J M, Sharma D. Estimates of natural cross-pollination in Cajanus cajan (L.) Millsp.: several experimental approaches. In: Proceedings of Workshop on Pigeonpeas. Patancheru, Andhra Pradesh, India: International Crops Research Institute for the Semi-Arid Tropics, 1980. pp $129-136$

[12] Deshmukh N Y, Rekhi S S. Study of natural cross-pollination in pigeonpea [Cajanus cajan (L.) Millsp.]. Proc Bihar Agric Sci, 1962, 8: 135-139

[13] Kadam B S, Kulkarni R M, Patel S M. Natural crossing in Cajanus cajan (L.) Millsp. in the Bombay Deccan. Indian $J$ Genet, 1945, 13: 90-95

[14] Prasad S, Prakash R, Hassan M A. Natural crossing in pigeonpea [Cajanus cajan (L.) Millsp.]. Mysore J Agric Sci, 1972, 6: 426-429

[15] Wilkie C P, Takahashi M. Natural crossing in pigeonpea. $J$ Agric Res, 1984, 49: 923-927

[16] Zong X X, Saxena K B. Progresses on research and usage of pigeonpea heterosis. Crops, 2006, (5): 38-40 (in Chinese)

[17] Williams I H. Behaviour of insects foraging on pigeonpea [Cajanus cajan (L.) Millsp.]. Trop Agric, 1997, 54: 353-363

[18] Li Z H, Zhang Q, Yang C F, Ma H, Liu X X. Evaluation of agronomic and quality aspects of pigeonpea hybrid varieties. For Res, 2009, 22: 500-505 (in Chinese)

[19] Wang Y. Agrometeorology and Agroclimatological Resources and Regional Planning in Yunnan Province. Beijing: China Meteorological Press, 1990 (in Chinese)

[20] Kuang B Y, Kuang H O. Biology of Bees. Kunming: Yunnan Science \& Technology Press, 2003. pp 220-221 (in Chinese)

[21] Liu Y Q. Overview on infecting aspects of bee pollinating. $J$ Bee, 1997, (4): 26-27 (in Chinese) 